\title{
The Roles of Foreign Aid and Education in the War on Terror
}

\author{
by
}

Jean-Paul Azam $^{\mathrm{a}}$ and Véronique Thelen ${ }^{\mathrm{b}}$

a: Toulouse School of Economics (ARQADE \& IDEI) and Institut Universitaire de France, b : Toulouse School of Economics (ARQADE).

\begin{abstract}
This paper presents a theoretical framework and some empirical results showing that the level of foreign aid received reduces the supply of terrorist attacks by recipient countries, as does the recipient country's level of education. Due account is taken of endogeneity problems in producing these results. They suggest that Western democracies, which are the main targets of terrorist attacks, should invest more funds in foreign aid with a special emphasis on supporting education.
\end{abstract}

Keywords: Terrorism . Foreign aid . Education

\section{Corresponding Author:}

Professor Jean-Paul Azam, ARQADE, University of Toulouse 1, 21 Allée de Brienne, 31000 Toulouse, France.

E-mail : azam@univ-tlse1.fr 


\section{Introduction}

In the last few decades, terrorism has mainly involved attacks on economic or political interests of rich and democratic countries perpetrated by nationals from developing countries (Krueger and Laitin, 2003). ${ }^{1}$ Terrorism thus has an important international dimension, as most incidents relate a target country to a different source country, and that relationship is typically asymmetrical. The two countries involved have vastly different levels of economic and political development. Often, the terrorist attack takes place in yet another host country, which Drakos and Gofas (2006) call the "venue". Therefore, the target country is not necessarily in a position to defend its interests directly, and must delegate part of its antiterrorist activity to one or several governments, unless it deliberately infringes on the latter's sovereignty. This inter-governmental relationship has generally been neglected in the literature devoted to the fight against terrorism. The latter has mainly addressed the issues of self-protection against terrorist attacks (see Enders and Sandler, 2006) and of “crackdown”. One exception is Azam and Delacroix (2006), who suggest that foreign aid is important for inducing local governments to fight terrorism within their sphere of influence. They first bring out a surprising empirical relationship where the aid flow received by a country is positively correlated with the number of terrorist attacks flowing from it, after controlling only for the recipient country's level of income per capita and population size. Furthermore, they provide a simple theoretical analysis and an econometric test showing that the latter relationship is not a structural equation but an equilibrium locus relating two endogenous variables. This result and its theoretical underpinnings suggest that donor countries are actively using foreign aid as a tool in the war on terror. Within that framework, the donor community is allocating aid

\footnotetext{
${ }^{1}$ Kurrild-Klitgaard et al. (2006) confirm that democracies tend to be the target of terrorist attacks, with a quadratic effect reaching a maximum at very high levels of democracy. Beyond that point, more democracy reduces the number of attacks. They also show that democracy reduces the probability that a terrorist attack originates in any given country. By contrast, Basuchoudhary and Shughart (2007) show that political rights are not consistently significant in their sample, while the lack of economic freedom is a key characteristic of source countries.
} 
across countries to provide (among other things) stronger incentives for fighting terrorism to governments facing more militant groups. They then show that a few dummy variables are sufficient for controlling somewhat for "militancy" and producing a structural equation including a negative impact of aid on the supply of attacks by source countries. The present paper presents a more satisfactory structural-form equation, with a richer theoretical framework, explaining better the role of aid in the fight against terrorism. It presents some stronger estimates for the role of aid and brings out the impact of secondary school enrollment in reducing the number of terrorist attacks by country of origin.

This debate about the role of foreign aid in the war on terror emerged recently at the highest political level. George W. Bush advocated its use as a tool against terrorism in a much cited speech in Monterrey on March 22, 2002. He then said: "We fight against poverty because hope is an answer to terror” (cited in Krueger and Maleckova, 2003, p.119). This idea was echoed in various quarters of the U.S. administration, as well as in academia, and some of its implications were drawn for strengthening aid policy. The Millennium Challenge Account was created as a new tool for channeling aid to poor countries in the wake of that speech. Alan Krueger criticized this proposition in an influential op-ed published in the New York Times (Krueger, 2003). The bottom line of his criticism is that poverty does not seem to be the main determinant behind terrorist attacks. The survey data presented in Krueger and Maleckova (2003), as well as in Krueger and Laitin (2003), show in fact that terrorists from different movements, including the Hezbollah, are predominantly recruited from a relatively wealthy and educated family background. Similarly, the biographies of Al-Qaeda's activists analyzed by Sageman (2004) show that they generally have a high level of education, mostly in scientific or technical disciplines. Hassan (2001) describes a sample of Hamas volunteers with a similar background. Moreover, she shows that they are given some intensive religious training after having enrolled for a suicide mission. Some other insights on the profiles of terrorists can be gleaned from Bloom (2005), Reuter (2004) and Stern (2003). The emerging 
picture is that terrorists are men and women in their twenties with some post-secondary training, mostly in technical or engineering education. Hence, the microeconomic evidence refutes a simple view that poverty breeds terrorism, because terrorists are not recruited among the poorest segments of their society of origin. A simple reading of these results would suggest instead that wealth and education exert a positive influence on the decision to engage in terrorist attacks. Similarly, Paz (2000) documents the fact that higher education expanded throughout the West Bank and Gaza at the time when the Hamas and Islamic Jihad were gaining popular support. However, the supply of skilled jobs was not expanding in proportion, raising some doubt about the significance of this co-movement. Nevertheless, this debate is bearing on a fundamental aspect of the relationships between the North and the South. It raises the issue of the continuation of foreign aid, insofar as it is supposed to support education and contribute to growth, while the global fight against terrorism is dominating international relations. The present paper aims at contributing some additional arguments in this debate, using both theoretical and empirical analysis.

President Bush advanced a different line of defense for his views about poverty and terrorism in September 2002. In a New York Times op-ed published on September 11 he wrote: "Poverty does not transform poor people into terrorists and murderers. Yet, poverty, corruption and repression are a toxic combination in many societies, leading to weak governments that are unable to enforce order or patrol their borders and are vulnerable to terrorist networks and drug cartels” (cited in Krueger and Maleckova, 2003, p.140). This statement identifies the government as the crucial actor whose behavior creates the link between economic conditions and terrorism. However, his use of the expression "weak government” might be misleading. Krueger and Maleckova (2003) and Krueger and Laitin (2003) have found that repressive states are typical of the countries of origin of the perpetrators in a cross-country regression estimated over the period 1997-2002. This raises a semantic issue, as one can make a case that strong states don't need repression, and are better 
equipped for securing civil liberties for their citizens. However, one potential concern with these findings that civil liberties have a negative impact on the supply of terrorist events is the endogeneity issue. Arguably, there probably are highly militant groups in the countries from which many terrorists originate, which might in turn lead their governments to adopt a repressive behavior. Frey (2004) argues that the government is facing a tradeoff between using repressive counter-terrorism measures ("the stick”) and relying on more social spending for reducing the social support to the terrorists ("the carrot”). More militant groups might care less for social support, especially if they have external sponsors (Siqueira and Sandler, 2006), thus pushing the government to choose more repressive methods. Hence, the presence of a repressive government and the supply of terrorists might in fact be jointly determined by the same cause, namely a high level of militancy among some groups in the population. The present paper draws two lessons from this debate, namely that a careful analysis of the role of the government is needed for understanding the links between aid and terrorism, and that the endogeneity issue is crucial for a proper empirical diagnosis.

The empirical analysis of the number of terrorist events has become a very active field of research. Todd Sandler has pursued this line of research over about two decades with various co-authors, and has published recently a synthesis of his findings (Enders and Sandler, 2006). These results have brought out the time-series properties of terrorist events, and shown the effectiveness of various countermeasures used by the West. They raise the issue of deflection, whereby self-protection by some countries diverts the flow of terrorist attacks to other countries. Krueger and Laitin (2003) and Krueger and Maleckova (2003) have focused instead on the flow of terrorist attacks originating from different countries and found that the key determinant is the presence of a repressive state in the source country. They underplay the role of economic variables, supporting the view that political determinants are more important. Similarly, Testas (2004) focuses on political repression rather than on income per capita, which he finds marginally significant or insignificant in a sample of Muslim 
countries. He finds that the impact of political repression on the supply of terrorist events is non-monotonic, as both low and high levels of repression have a positive impact. Abadie (2006) also finds a non monotonic impact of the lack of political rights, using the World Market Research Center’s Global Terrorism Index as the dependent variable. This is a risk rating index produced by an international risk agency. However, Azam and Delacroix (2006) suggest that political repression and the supply of terrorist attacks are jointly determined, both responding positively to the unobserved level of "militancy" prevailing in some groups in the source country. However, although terrorists are found in the upper tail of the income distribution, as mentioned above, some empirical studies suggest that the occurrence of terrorist attacks is negatively correlated with shifts of that distribution. Several empirical papers have shown that economic downturns are significant for explaining upsurges of terrorist attacks (Blomberg et al. 2004, Li, 2005). Hence, the macroeconomic evidence seems to contradict the findings emerging from individual data. Moreover, Basuchoudhary and Shughart (2007) find that it is economic freedom and secure property rights that reduce the number of terrorist attacks by source countries, rather than political rights. Lastly, Azam and Delacroix (2006) suggest that these analyses suffer from an omitted-variable bias, as Official Development Assistance (ODA) is significant in their own structural equation. Hence, even if foreign aid was ineffective in raising the recipient's national income or its level of education, it could have an impact by some other channels. The present paper offers a possible solution to this problem.

Frey et al. (2006) have criticized the standard practice of counting the number of terrorist events for adding up some very heterogeneous events. They argue that evaluating their costs would provide a more relevant measure of the severity of terrorist activity that would offer a more sensible way for computing an aggregate index. Crain and Crain (2006) provide an estimate of the GDP losses entailed by terrorism, suggesting that counter-terrorism has a high social return. Moreover, Frey et al. (2006) show that non-economic losses 
represent a significant component of the social cost of terrorist events. A more lethal event would reduce life satisfaction by a larger amount than a less lethal one, over and above any economic loss experienced by the survey respondents. Hence, a correct measurement of the damage inflicted by the terrorist events would give more weight to the more lethal and violent attacks, focusing attention on the most damaging ones. Nevertheless, an empirical analysis of the number of events originating in each country remains a useful task to perform in order to identify the possible policy handles available for reducing their flow. The measurement of the social cost of terrorism is probably more relevant for the target or the host country than for the source country, which is the aim of the analysis presented below. We focus here on the crosscountry determinants of the number of terrorist attacks by country of origin.

The individual-level findings described above about the impact of wealth on terrorism also raise a major challenge to rational-choice theorists. Higher wealth and education increase the opportunity cost of taking risk in perpetrating a terrorist attack, and still do not deter those who cross the line. Three main arguments have been offered to reconcile this finding with rationality. The first one is based on the assumption of rationing on the volunteers' market; there is an excess supply of volunteers for terrorist missions, and the organizations pick the most educated ones, likely to be more efficient than the others. Bueno de Mesquita (2005) has developed this line of analysis, suggesting that policies improving the economic situation, including, perhaps, foreign aid, could nevertheless play a favorable part in reducing mobilization and violence. His model predicts that we could observe both the micro-result described above that terrorists have an above-average educational level, and the opposite macro-level effect, namely that an increase in the general level of education in the population could reduce the supply of terrorist attacks. This would work indirectly, through a reduced level of mobilization impacting on the terrorist organization's incentives. A different argument is used by Azam (2005), assuming that terrorists are motivated by altruism towards the next generation. People with a lower rate of time preference will invest more resources in 
education, and will also be more willing to sacrifice their own lifes for the sake of the future generation. Hence, the effect of education on the opportunity cost of putting one's life at risk might be offset by its positive impact on inter-generational altruism. That model suggests that some types of aid policies might be effective against terrorism, depending on the effect that they have on the tradeoff facing the potential terrorists. Here as well, the impact of a higher level of education in the population on the supply of attacks cannot be signed unambiguously, while the most educated ones would still be more involved than the others. Berman and Laitin (2005), Ferrero (2006) and Wintrobe (2006) provide a third line of argument, and analyze instead the social pressure dimension of the decision to opt for suicide bombing. More educated people would be more sensitive to some kind of social pressure, especially when they are students living far away from their families. They then tend to create a closed circle with other students. Sageman (2004) illustrates this phenomenon with examples from AlQaeda activists. The Hamas volunteers described by Hassan (2001) provide a slightly different picture, where social pressure is more diffuse and pervasive. However, she shows that intensive religious training only comes after the decision to go for a suicide mission has been taken. These models do not have strong implications for aid policy. The four papers cited above (Azam, Berman-Laitin, Ferrero and Wintrobe) view suicide attacks as the ultimate test of the rational-choice approach to terrorism. The present paper does not address empirically this issue, but the theoretical framework takes due account of these findings that education might have a positive impact on the value that some activists attach to performing a terrorist attacks. ${ }^{2}$

The next section briefly reviews the literature on the allocation of foreign aid across countries, which suggests that the latter is predominantly determined by political considerations, rather than by the aim of fighting poverty per se, despite declarations to the

\footnotetext{
${ }^{2}$ Moreover, all these papers analyze the micro-foundations of terrorism in general, while the present one is restricted to transnational terrorism. It seems safe to assume that their predictions extend to this setting as well.
} 
contrary. Section 3 presents the simple model that captures the delegation problem involved in the fight against transnational terrorism. It is aimed at bringing out the roles of foreign aid

and education in the war on terror. The empirical results are presented in two steps. Section 4 presents the data used and a simple estimation of the impact of aid and education on the number of attacks originating from each country. Section 5 provides a slightly more sophisticated analysis, directed at testing whether an endogeneity bias is present in that equation. Section 6 offers some concluding comments.

\section{The Political Determinants of the Allocation of Foreign Aid across Countries}

As mentioned above, a careful analysis of the role of the government is needed for understanding the links between aid and terrorism. This is consistent with the theoretical literature on aid, which is largely couched in the framework of the principal-agent model. There is now a sizable literature discussing various aspects of aid, which has percolated somewhat in the policy debate (e.g., World Bank, 1998). The basic structure of the theoretical model of aid views the recipient government as the agent of a foreign power, the donor. Both players have some common interest, which is widely assumed to be poverty alleviation, albeit with different weights (Adam and O’Connell, 1999, Azam and Laffont, 2003, Svensson, 2000 and 2003). Any other common interest could be included in the model, without changing the basic structure. Then, the aim of the analysis is to bring out the implementation problems involved and to discuss solutions that can make aid effective, by the donor's standards. Azam and Saadi-Sedik (2004) go one step further by looking at the foreign power's choice between giving aid and imposing sanctions. They provide a case study of the Iraqi Kurds after the “Provide Comfort” operation protected them against Saddam Hussein's persecution, and conclude that they benefited from some economic growth under the allied forces' military shield. Section 3 uses a simple instance of such a principal-agent model where the donor is using the recipient government as a delegate for performing some tasks on its behalf. 
The empirical literature on the allocation of aid across developing countries takes on board the political economy dimension. Aid to developing countries has been increasingly delivered as program aid, conditional upon the recipient government undertaking various policy reforms. The influential paper by Burnside and Dollar (2000) has brought out that the effect of aid must be analyzed while taking due account of some heterogeneity among recipient countries. They favor an index of the quality of macroeconomic policies as their heterogeneity parameter. However, their results suggest that aid-effectiveness, as measured by its impact on growth, is not the key determinant of the allocation of aid across countries. Using also cross-country regression analysis, Svensson (1999) shows that aid is more effective in affecting growth in more democratic countries, but is not allocated to the latter more favorably. This also suggests that aid allocation is governed by other considerations. There is thus probably a hidden agenda beside the generous drive to alleviate poverty.

This issue is analyzed by Alesina and Dollar (2000), who show that colonial history and strategic alliances are the main determinants of the amount of aid received. They also show that, in the time-series dimension, democratization is often followed by increased aid, although there is no significant static effect of democracy. By contrast, Berthélemy and Tichit (2004) find a significant positive impact of the Freedom House index of civil liberty and political rights, in a panel data analysis over the period 1980-1999, for 137 aid recipient countries and 22 bilateral donors. This is confirmed in Berthélemy (2006), using a different estimation method. The latter two studies bring out that most bilateral donors are also guided by their self-interest in allocating their aid, and in particular by their commercial relationships. Fleck and Kilby (2006a) show that the latter play also an important part in determining the allocation of U.S. bilateral aid across countries, while more conservative presidents are more influenced by commercial interests than more liberal ones. Fleck and Kilby (2006b) suggest that such a diagnosis can be extended to the case of the World Bank, whose aid-allocation behavior is significantly influenced by U.S. trading and political 
interests. However, one may wonder whether trading flows are exogenous. Although most bilateral donors have formally ruled out tied aid, towards the end of that sample period, some implicit and subtle ways of tying aid likely remain in operation. Moreover, aid helps financing the trade deficit of developing countries, and this is boosting their imports from industrialized donors. Hence, some reverse causation between aid and trade might also be at work.

Chauvet (2002) looks at the relationship between aid allocation across countries and socio-political instabilities. She shows that the aid flow is somewhat directed at governments that are under political threat, while it shies away from the threats that are directed more specifically at the economy. This is related to the finding by Collier (2007) that a nonnegligible fraction of aid leaks out financing the military, without much effort by donors to avoid it, while aid is pretty ineffective at lifting people out of poverty. These results again support the view that donors are politically motivated when giving aid, while economic issues play a secondary role. Similarly, Azam and Delacroix (2006) show that aid allocation across countries is influenced by the donors' goal of fighting terrorism.

The present paper also analyzes a political dimension of the allocation of aid across countries, by looking at its relationship with terrorism. Instead of looking at the indirect link between aid and poverty, and then in turn to the additional link between poverty and terrorism, as done in the policy debate mentioned above, we are looking here at the direct link between aid and terrorism.

\section{The Model}

We model a donor that allocates aid between a number of countries, which are liable to produce some terrorist attacks against the donor. In each of these countries, the government is able to exert some effort to fight terrorism, at a cost. Then, aid is a way to defray the recipient government for this cost of effort. The government's action exerts its influence on the value of a terrorist "hit" for the activists, which also depends on some idiosyncratic 
“militancy” parameter. Hence, for each country, three players are involved: (i) the terrorist group determines the number of attacks perpetrated against the donor, (ii) the local government exerts some effort to deter these actions, while (iii) the donor provides some aid for compensating the government. This model is an extension of the one presented in Azam and Delacroix (2006) ${ }^{3}$ aimed at capturing the choice between the "carrot" and the "stick" as a way of controlling terrorism in the aid-recipient country.

\section{The Three Agents}

We capture this framework using the following specification. Denote $Y$ the given income of the donor, $A$ the total amount of aid delivered, and $H$ the total number of terrorist attacks hitting the donor and coming from the different countries. Assume that the donor incurs a cost $\psi(H)$ because of these attacks, assumed increasing and convex. Now, denote $a_{i}$ the aid given to country $i \in\{1, \ldots, n\}$, and $h_{i}$ the number of attacks originating in $i$. Then, by definition, $A=\sum_{i} a_{i}$ and $H=\sum_{i} h_{i}$. The donor is also assumed to split its aid flow between general budget support to the government denoted $b_{i}$ and an amount $s_{i}$ which is earmarked for supporting education. The latter captures the social concern expressed by the donor in its relationship with the recipient government. Hence, $a_{i}=b_{i}+s_{i}, \forall i$.

Country i's government values the aid flow $b_{i}$ as well as the level of human capital achieved in the country denoted $k_{i}$. The latter produces a level of utility $u\left(k_{i}\right)$ (assumed increasing and concave) for the government, which is meant to capture all the positive fallout of human capital, built up through education and health, ranging from the improved social welfare to the increased fiscal resources that a more skilled population is liable to pay. This utility function thus captures both the pecuniary and non-pecuniary benefits that the ruler gets from the level of human capital present in his country. The unit cost of producing this level of human capital is denoted $\delta\left(s_{i}, \varepsilon_{i}\right)$, which is decreasing in the donor's earmarked contribution

\footnotetext{
${ }^{3}$ The working paper version of that paper is longer and more comprehensive than the published one, and is available as IDEI Working Paper No. 324 at http://idei.fr.
} 
$s_{i}$ and in the country's own past investment in human capital, which we call educational capital from now on, denoted $\varepsilon_{i}$. The latter captures all the social and physical infrastructure that the country has in the education (and health) sector, including its cultural traditions, its schools and universities, as well as its stock of trained teachers, etc. The donor's earmarked contribution to the education sector $s_{i}$ is modeled here as reducing the cost of expanding human capital borne by the government. This specification entails that such an earmarked contribution to the education sector is not perfectly fungible with either local funds or other aid flows. This may capture, for example, the use of differentiated inputs like highly qualified teachers, without local substitutes, that would not be available without the donor's intervention, or scholarships for joining select institutions abroad. We can thus define the government's profit from human capital investment as:

$$
\pi\left(s_{i}, \varepsilon_{i}\right)=\max _{k_{i}} u\left(k_{i}\right)-\delta\left(s_{i}, \varepsilon_{i}\right) k_{i} .
$$

It is easily checked that this profit function is increasing in its two arguments, reflecting the cost-saving effects of both the local educational capital and the donor's earmarked contribution. Applying Hotelling's lemma, (1) implies that country $i$ 's human capital level may be written as an increasing function of $s_{i}$ and $\varepsilon_{i}$ :

$$
k_{i}=k\left(s_{i}, \varepsilon_{i}\right) .
$$

The country's government also incurs a cost $\xi\left(r_{i}\right)$ (assumed increasing and convex) when performing an amount $r_{i}$ of repression against terrorists, with $\xi(0)=0$. Then, the aid contract will specify how much repression the local government is expected to perform against the terrorists within its sphere of influence in return for the aid received, including the earmarked contribution to the education sector. This view of the aid contract captures the idea that the foreign power has to delegate part of the protection of its interests against terrorism to local governments, using aid as a means of defraying the costs of doing so incurred by the 
local government. In order for this contract to be acceptable by the latter, the triplet $\left\{b_{i}, s_{i}, r_{i}\right\}$

must fulfill the following government's participation constraint, where we normalize $\pi\left(0, \varepsilon_{i}\right)=0$ :

$$
b_{i}+\pi\left(s_{i}, \varepsilon_{i}\right)-\xi\left(r_{i}\right) \geq 0 \text {. }
$$

Let $h_{i}$ be the number of attacks perpetrated by country $i$ 's terrorist organization against the foreign power's interests. The terrorist organization attaches a unit value $\theta_{i} v\left(k_{i}\right)$ to these attacks, where $\theta_{i}$ is the "militancy" parameter, assumed known to both the donor and the government, and $v\left(k_{i}\right)$ is an increasing function capturing the positive impact of human capital on the value attached by the terrorist organizations to the attacks perpetrated against the foreign power's interests. This positive effect of human capital on the value of terrorist attacks for the perpetrators is meant to capture the fact mentioned in the introduction that terrorists generally have an above-average education level, as first pointed out by Krueger and Maleckova (2003) and Krueger and Laitin (2003). The terrorist organization is also incurring a cost $\omega\left(h_{i}, k_{i}, r_{i}\right)$ for perpetrating its attacks. This cost function is naturally assumed to be increasing and convex with respect to $h_{i}$, and increasing in $r_{i}$. The impact of $k_{i}$ is less clearcut, and probably combines two opposing effects. There is first a positive impact, as more educated people have a higher opportunity cost, which the terrorist organization will most probably take into account. There is then a second impact going in the other direction, as more educated people are probably more efficient at performing the attacks. The latter effect has been analyzed by Bueno de Mesquita (2005), as discussed in the introduction. However, we do not need to make a firm assumption regarding the marginal effects of repression and education on the terrorist organization's costs, as they do not affect the model's main predictions. The latter only depend on the cross-second partial derivatives, i.e., the impact of these variables on the marginal cost of perpetrating an attack for the terrorist organization. It 
is natural to assume that repression increases the marginal cost of perpetrating an attack. Denoting cross-second derivatives by subscripts, this means that $\omega_{h r}>0$.

The time line of the game is as follows: (i) the donor offers the aid contract described above; (ii) the government exerts the agreed level of repression and chooses its preferred education level, both assumed to be perfectly observable and contractible by the two parties; (iii) the terrorists launch their chosen number of attacks $h_{i}$; and lastly (iv) the aid is delivered and consumed. Hence, this game can be solved by backward induction. We first derive the terrorist organization's best-response function, as a function of the government's policy variables. Then, the "attacks supply curve" is derived at the country level, by bringing in the government's preferred mix of repression and education expenditures, taking due account of the donor's influence on that choice.

The terrorist organization chooses its level of attacks $h_{i}$ with a view to maximizing:

$$
\theta_{i} v\left(k_{i}\right) h_{i}-\omega\left(h_{i}, k_{i}, r_{i}\right)
$$

Then, its best-response function $h_{i}=h\left(\theta_{i}, k_{i}, r_{i}\right)$ may be derived from the first-order condition $\theta_{i} v\left(k_{i}\right)=\omega_{h}\left(h_{i}, k_{i}, r_{i}\right)$, where $\omega_{h}(-)$ denotes the derivative of the cost with respect to the level of attacks. Denoting $\omega_{h h}>0, \omega_{h r}>0$ and $\omega_{h k}$ the relevant second derivatives of the cost function, the latter implies:

$$
\frac{\partial h_{i}}{\partial \theta_{i}}=\frac{v\left(k_{i}\right)}{\omega_{h h}(-)}>0, \quad \frac{\partial h_{i}}{\partial r_{i}}=\frac{-\omega_{h r}(-)}{\omega_{h h}(-)}<0 \quad \text { and } \quad \frac{\partial h_{i}}{\partial k_{i}}=\frac{\theta_{i} v^{\prime}\left(k_{i}\right)-\omega_{h k}(-)}{\omega_{h h}(-)} \text {. }
$$

The signs of the first two partial effects on the left-hand side are fairly intuitive, and do not call for much comment: more militant groups produce more attacks, while a greater repression effort by the government reduces the number of attacks. The third effect is ambiguous, as more human capital increases the value of terrorist attacks while its impact on the marginal cost of these attacks is itself ambiguous, as discussed above. As mentioned in the introduction, this ambiguity is compatible with the predictions of either Bueno de Mesquita 
(2005) or Azam (2005) concerning the macro-impact of education on the level of terrorist activity.

\section{The Attacks Supply Curve}

Now, the donor will choose its preferred aid contract with a view to maximizing $Y-A-\psi(H)$ over all countries, subject for each one of them to the terrorists' best-response function $h_{i}=h\left(\theta_{i}, k_{i}, r_{i}\right)$, the government's preferred human capital investment policy $k_{i}=k\left(s_{i}, \varepsilon_{i}\right)$ and the government's participation constraint (3), which may be written as:

$$
a_{i} \geq s_{i}-\pi\left(s_{i}, \varepsilon_{i}\right)+\xi\left(r_{i}\right) .
$$

This problem can be decomposed into two steps:

(i) Aid composition problem: the efficient attacks supply curve is determined for each country by minimizing $h_{i}$, using $s_{i}$ and $r_{i}$ as control variables, given the level of $a_{i}$, the local government's participation constraint (6), its preferred education policy (2), and the terrorist organization's best response function. ${ }^{4}$

(ii) Aid allocation problem: the donor's optimal allocation of aid across countries is determined by minimizing $A+\psi(H)$, taking all the efficient attacks supply curves as constraints. $^{5}$

The donor has no reason to leave any positive rent to the local government, and thus (6) will hold with equality. Then, solving simultaneously these three equations allows us to establish proposition 1.

Proposition 1: (i) The number of terrorist attacks originating from country $i$ can be written as the following attacks supply curve:

\footnotetext{
${ }^{4}$ The second-order condition for this problem is messy, and involves second- and third derivatives for which not much intuition seems compelling. It requires the terrorists' best-response function to be quasi-convex in $s_{i}$ and $r_{i, \text {, }}$ after substituting for the employment policy, and the government's participation constraint to be concave in the same space. We simply assume that it holds in the relevant neighbourhood.

${ }^{5}$ The second-order condition required here is not more enlightening than at the previous footnote. It essentially requires the efficient attacks supply curves derived at (7) below to be convex in $a_{i}$.
} 


$$
h_{i}=h\left(\theta_{i}, \varepsilon_{i}, a_{i}\right),
$$

such that, denoting $\lambda_{i}>0$ the Lagrange multiplier associated with the government's participation constraint:

$$
\frac{\partial h_{i}}{\partial \theta_{i}}=\frac{v\left(k_{i}\right)}{\omega_{h h}(-)}>0, \quad \frac{\partial h_{i}}{\partial \varepsilon_{i}}=\frac{-\lambda_{i} \partial \delta / \partial \varepsilon_{i}}{\partial \delta / \partial s_{i}}<0 \quad \text { and } \quad \frac{\partial h_{i}}{\partial a_{i}}=-\lambda_{i}<0 .
$$

(ii) The donor's optimal allocation of aid across countries is determined by setting:

$$
\lambda_{i}=1 / \psi^{\prime}(H), \quad \forall i \in\{1, \ldots, n\} .
$$

Proof: Proposition 1 (i) is established by minimizing the terrorists' best-response function $h_{i}=h\left(\theta_{i}, k_{i}, r_{i}\right)$ subject to the government's preferred education policy $k_{i}=k\left(s_{i}, \varepsilon_{i}\right)$, and the government's participation constraint written as an equality $a_{i}=s_{i}-\pi\left(s_{i}, \varepsilon_{i}\right)+\xi\left(r_{i}\right)$. The first-order conditions for this problem yield:

$$
\frac{\partial h_{i}}{\partial k_{i}}=\frac{\lambda_{i}\left(\left(\partial \pi / \partial s_{i}\right)-1\right)}{\partial k_{i} / \partial s_{i}} \text { and } \frac{\partial h_{i}}{\partial r_{i}}=-\lambda_{i} \xi^{\prime}\left(r_{i}\right) \text {. }
$$

Then, the first-order condition for the government's problem (1) can be used to derive the following partial derivatives:

$$
\frac{\partial \pi}{\partial s_{i}}=-k_{i} \frac{\partial \delta}{\partial s_{i}} \text { and } \frac{\partial k_{i}}{\partial s_{i}}=\frac{\partial \delta}{u "\left(k_{i}\right) \partial s_{i}},
$$

which can be substituted in (10). The resulting expression can then be used with the terrorist organization's best response function and the government's participation constraint to yield the derivatives given in (8) by taking their total differential and rearranging the terms.

Then part (ii) is established by minimizing $A+\psi(H)$, taking all the efficient attacks supply curves as constraints.

A noticeable property of the attacks supply curve, as expressed in (8), is that the signs of the impacts of the educational capital and of aid do not depend on the terrorists' 
parameters, once (9) is taken into account, but only on the cost functions entering the donor's and the government's objective functions. In particular, the fact that the value attached by the terrorists to the attacks $v\left(k_{i}\right)$ was assumed above to be increasing in the level of human capital is irrelevant for these predictions. This suggests of course that the observed fact that terrorists have an above-average education level mentioned in the introduction is irrelevant for aid policy. Proposition 1 tells us that even in that case, more educational capital ends up reducing the number of terrorist attacks at the cross-country level, because its effect is more than compensated by an adjusted level of repression; for a given aid level, a higher level of educational capital allows the local government to reach its human capital objective at a lower cost, and thus frees some resources for performing more repression. ${ }^{6}$ Hence, for some values of the parameters, it is possible that the donor will elicit more repression from the government by earmarking more funding to education

\section{Empirical Analysis}

We test the main predictions of the model described above using a dataset similar to the one used by Krueger and Maleckova (2003) and Krueger and Laitin (2003), based on the same source. We thus focus on the number of terrorist events per country of origin of the perpetrators ${ }^{7}$. These data are available on the internet, in the database provided by the International Policy Institute for Counter-Terrorism (ICT). We have extended the sample used in the two Krueger et al. papers cited above to cover the period from January 1990 to March 2004. More precisely, the number of terrorist events is computed from a set of 1119 terrorist incidents, taking place between January 1990 and March 2004 ${ }^{8}$ (Azam and Delacroix, 2006). All these events are transnational in that the target and the source countries are different. These terrorist attacks are aggregated over the period mentioned above to produce a number

\footnotetext{
${ }^{6}$ The appendix wraps up the theoretical analysis by explaining how the $a_{i}$ s and $H$ are jointly determined.

${ }^{7}$ Hence, a terrorist attack perpetrated by two terrorists from different countries is counted as two events.

${ }^{8}$ Alexandra Delacroix has produced this data set when she was a DEA student at Toulouse University.
} 
of attacks originating from each country during that period. During the latter, the terrorist attacks originated from 80 source countries in our sample, as we have excluded Afghanistan, Bosnia, Cuba, Myanmar, Somalia and Yugoslavia, for lack of some data on the explanatory variables. Thus, we are left with the source countries of terrorist attacks accounting for slightly less than half the 176 countries in our sample. Table A1 in the appendix gives the full list of the number of attacks by country of origin used in our estimations. Only 18 countries are the source of more than 18 attacks, while 18 countries are the source of only 1 event over that period. Not surprizingly, the West Bank and Gaza Strip provide the largest number of attacks, with 400 terrorist events originating there. However, the Middle East is not the only source of terrorism as Sub-Saharan Africa, South Asia, Europe and Latin America are all represented in the top-10 source countries. Many OECD countries are also the source of terrorist attacks, including France, the U.K. and the U.S.A.

The main goal of our empirical analysis is to test the predictions that foreign aid and educational capital have a negative impact on the supply of terrorist attacks originating in the recipient counntries. We use the standard measure of foreign aid, namely Official Development Assistance (ODA). This variable aggregates the disbursements of loans (with a high enough grant component) and grants by official agencies of the members of the Development Assistance Committee (DAC) to promote economic development and welfare in the recipient countries. These data are measured in constant 2000 U.S. dollars. In the sample used in this article, 24 countries are aid donors, mainly among OECD member countries. The model presented above suggests that this is an endogenous variable, insofar as the donor is allocating aid with a view to controlling the supply of terrorist attacks from recipient countries. Moreover, there is no compelling argument for deciding whether ODA should be measured per capita or as a ratio to GDP. While the former specification seems to capture better the potential benefits that the country will get from aid, the latter seems more appropriate for measuring the need for it. Consequently, we use both specifications in what 
follows, showing that the standard econometric procedure for choosing between two nonnested hypotheses is not conclusive in this case. It is less straightforward to find the right measure of educational capital in a comparable way across countries. We have chosen to use the enrollment rate in secondary education in our main equation, but the appendix presents some robustness checks. This variable is thus liable to be endogenous on two accounts. First, the theoretical model above predicts that the donor will earmark some funds for influencing the decision of the local government to fight terrorism within its sphere of influence by reducing the cost of investing in education. Second, this variable is bound to measure educational capital inaccurately, and thus to include some measurement error entailing a correlation between the included variable and the residuals. Both ODA and secondary school enrollment are probably correlated with the level of economic and political development of the recipient countries. It is thus important to control for the latter in order to mitigate the risk of finding a spurious correlation with aid and education due in fact to under-development. We use GDP per capita and population size as controls in our regressions. GDP in constant 2000 U.S. dollars is divided by midyear population. However, because repression is endogenous in our theoretical framework, and optimized out for deriving the structural equation (7), we do not include a control variable capturing civil liberty or democracy. The latter are implicitly determined by the exogenous variables in the model, like militancy and educational capital, and the level of foreign aid.

The source of data for all these explanatory variables is the World Bank's World Development Indicators online (WDI). We use a sample of 176 countries, averaging population, GDP per capita, ODA per capita, ODA as a percentage of GDP and secondary school enrollment over the period 1990-2004. Table A.2 in the appendix provides some summary statistics for these data. ODA per capita is Official Development Assistance divided by the midyear population size. A majority of countries have an ODA per capita between 0 and 50 dollars. Countries receiving more than 100 dollars per capita are the poorest among the 
developing countries. The majority of countries with a ratio of ODA to GDP higher than 30\% are in Sub-Saharan Africa. Dummy variables are used for indicating these countries, as a check on possible non-linearity or a differential treatment for them by the donors. For measuring the level of secondary education, we use the gross enrollment rate, i.e., the ratio of total enrollment, regardless of age, to the population of the relevant age group. The resulting ratio can therefore be higher than $100 \%$. The majority of countries have a gross percentage of secondary school enrollment between 90 and $100 \%$ but many countries have a much lower rate, especially in developing countries.

Finally, as emphasized by Azam and Delacroix (2006), it is very important to try to control for militancy in order to identify the correct structural equation for the attacks supply curve. The crucial element of their identification strategy is the sign of the impact of aid, which is negative in the structural equation, while there is a positive correlation across countries if no attempt is made to control for militancy. We follow the same route here and use some dummy variables as proxies for capturing this unobserved variable. ${ }^{9}$ After a little experimentation, the following dummy variables turned out to be useful: West Bank and Gaza, Camp David (Egypt and Israel), China and India, Latin American countries, ASEAN countries before 1990 (Indonesia, Malaysia, Philippines, Singapore and Thailand), OECD countries before 1990, Sub-Saharan African countries and former USSR countries. Of course, these dummy variables also control for other country characteristics that may affect the supply of terrorist attacks, like geography and civilization. Moreover, these variables can also capture some effects of the educational capital that are not captured by the secondary school enrollment rate.

The attack supply curve cannot be analyzed by standard least squares estimation because the dependent variable takes only non-negative integer values corresponding to the

\footnotetext{
${ }^{9}$ A potentially useful variable for capturing some aspects of this "militancy" level is the "ethnic tension" index that affects significantly the level of terrorist attacks by country of origin in Basuchoudhary and Shughart (2007). Testing for this falls outside the scope of the present paper.
} 
number of terrorist events, while most countries are the source of no attacks at all. The standard methods for analyzing such count data include the Poisson regression and the negative binomial model (Cameron and Trivedi, 1986). The latter is less restrictive than the former because it has one more free parameter. The assumed equality of the conditional mean and variance functions is the most restrictive assumption of the Poisson regression model. The negative binomial specification introduces an individual, unobserved effect into the conditional mean. According to this model individuals have a constant but unequal probability of experiencing an event. We use the latter specification, following McCullagh and Nelder (1983). We tested it against the Poisson model, and concluded that the negative binomial model is always preferred. Therefore, in the following analysis we only present the negative binomial results.

Both the theoretical model presented above and the econometric results presented in Azam and Delacroix (2006) conclude that the number of terrorist events by country of origin and the amount of aid are simultaneously determined. However, because it is well known that most methods aimed at correcting for the endogeneity bias are liable to reduce the efficiency of the estimators, we start the analysis by performing the estimations without taking care of it. In the next section, we then test whether these benchmark estimates are misleading by testing for the presence of a significant endogeneity bias.

Table 1 presents two different estimated equations of the number of terrorist events originating from each country, estimated on the 176-country sample and where the variable ODA is in percentage of GDP. Equation 1 includes population size as a control variable, which turns out to be insignificant. Equation 2 then is estimated while excluding population from the list of explanatory variables. This does not affect much the other coefficients. These equations provide some support for the two maintained hypotheses, as the ratio of ODA to GDP and secondary school enrollment have a significant impact with the predicted sign. Regarding the other control variables, per capita GDP shows up with a negative sign. This is 
consistent with casual observation, which suggests that terrorists mainly come from developing countries. As many characteristics of the level of economic and political development are known to be correlated with per capita GDP, one should not infer too much from this result. It does not imply that per capita income stricto sensu is a key factor in explaining the supply of terrorist events. Krueger and Maleckova (2003) have presented a strong argument against such a view. Nevertheless, it is a useful control variable to have, in order to disentangle the effect of foreign aid from that of under-development.

\section{Table 1: Number of Terrorist Events Originating From Each Country (With ODA in Percentage of GDP)}

\begin{tabular}{|c|c|c|c|c|c|c|}
\hline \multirow[b]{2}{*}{ Variables } & \multicolumn{3}{|c|}{ Equation 1} & \multicolumn{3}{|c|}{ Equation 2} \\
\hline & Coefficient & z-Statistics & p-value & Coefficient & z-Statistics & p-value \\
\hline Intercept & 3.454 & 4.72 & 0.000 & 4.382 & 6.32 & 0.000 \\
\hline Population & 4.12E-09 & 1.53 & 0.127 & - & - & - \\
\hline GDP p.c. & $-1.02 \mathrm{E}-04$ & -2.72 & 0.006 & $-1.11^{\mathrm{E}}-04$ & -2.82 & 0.005 \\
\hline ODA (\% GDP) & -0.088 & -3.04 & 0.002 & -0.110 & -3.62 & 0.000 \\
\hline \multicolumn{7}{|l|}{ Secondary enrollment } \\
\hline (\% gross) & -0.023 & -2.45 & 0.014 & -0.030 & -3.31 & 0.001 \\
\hline West B. Gaza & 6.228 & 2.92 & 0.003 & 6.366 & 2.88 & 0.004 \\
\hline "Camp David" & 3.833 & 2.46 & 0.014 & 3.806 & 2.35 & 0.019 \\
\hline Sub-Saharan & -0.519 & -0.81 & 0.415 & -0.799 & -1.21 & 0.228 \\
\hline OECD & 2.386 & 2.62 & 0.009 & 2.813 & 2.81 & 0.005 \\
\hline Nb. Obs. & 176 & & & 176 & & \\
\hline $\mathrm{R}^{2}$ & - & & & 0.590 & & \\
\hline Pseudo-R ${ }^{2}$ & 0.0736 & & & 0.064 & & \\
\hline LR-Stat chi2(7 df) & 57.63 & & 0.000 & 50.40 & & 0.000 \\
\hline
\end{tabular}

Note: Equation 1 and 2 are negative binomial regressions estimated by maximum likelihood.

Three of the dummy variables included are significant. The West Bank and Gaza dummy variable is an obvious candidate for being used as a proxy for "militancy". The estimates confirm that it is highly significant. The "Camp David” one, which indicates Egypt and Israel, also has a significant positive sign, which is less than $2 / 3$ as high as that for the 
West Bank \& Gaza Strip. Lastly, the dummy variable indicating the OECD countries also has a significantly positive sign, suggesting the presence of a high degree of militancy over the period considered. A glance at table A.1 shows that six OECD countries have produced at least six terrorist attacks, including Spain (31), Turkey (28), Greece (11), France (7), Ireland (6) and Italy (6). The importance of these dummy variables is confirmed by running these estimations without them. ${ }^{10}$ The results are shown in the appendix, where the equations run without the dummy variables have no significant likelihood ratio tests. Table A.3 presents this result for ODA as a percentage of GDP and ODA per capita. Hence, these dummy variables contain some relevant information for identifying our equation, although they most probably fall short of measuring "militancy” with any accuracy.

Table 2: Number of Terrorist Events Originating From Each Country (With ODA per Capita)

\section{Equation 3}

Variables

Intercept

Population

GDP p.c.

ODA p.c.

Secondary enrollment

(\% gross)
West B. Gaza
"CampDavid"
Sub-Saharan
OECD

Nb. Obs.

$\mathrm{R}^{2}$

Pseudo-R ${ }^{2}$

LR-Stat chi2 (7 df)
$-1.17$

3.79

3.88

$-1.75$

1.31

-0.010
8.216
6.325022
-0.963
1.116

176

0.0821

64.25

$\begin{array}{ccc}\text { Coefficient } & \text { z-Statistics } & \text { p-value } \\ 2.894 & 4.41 & 0.000 \\ 3.50 \mathrm{E}-09 & 1.60 & 0.109 \\ -8.02 \mathrm{E}-05 & -2.20 & 0.027 \\ -0.016 & -4.18 & 0.000\end{array}$

0.242

0.000

0.000

0.079

0.191

$$
0.000
$$

\section{Equation 4}

$\begin{array}{ccc}\text { Coefficient } & \text { z-Statistics } & \text { p-value } \\ 3.627 & 5.77 & 0.000 \\ -7.99 E-05 & -2.08 & 0.037 \\ -0.019 & -4.85 & 0.000\end{array}$

$-1.67$

0.094

8.617

3.84

0.000

6.663

3.96

0.000

$-1.392$

$-2.58$

1.102

1.18

0.236

176

0.073

57.47

0.000

Note: Equation 3 and 4 are negative binomial regressions estimated by maximum likelihood.

\footnotetext{
${ }^{10}$ The dummy variables for Sub-Saharan Africa and OECD are kept in the equations presented at tables 1 and 2 for the sake of comparison and testing because they are significant in either one or the other.
} 
Using ODA per capita instead of ODA as a ratio to GDP does not affect much the diagnosis, as shown by table 2 . The results are qualitatively the same as in the previous case, the same coefficients being significant with the same sign. Hence, we can draw the same conclusion regarding ODA and secondary education, although the latter is only significant at the $10 \%$ level when the insignificant population size is dropped, while it is not significant otherwise. Another difference is that now, it is the Sub-Saharan Africa dummy which is significant, while the OECD one becomes insignificant. Over the period 1990-2004 very few African countries are concerned with terrorism, while socio-political instabilities of another kind are endemic, including coup d'etat, civil wars and riots. One can observe that the majority of countries concerned by terrorist activities were not undergoing a civil war.

Hence, both equations lead to the same conclusion, namely that ODA, under both specifications, the secondary school enrollment rate, and GDP per capita negatively affect the supply of terrorist events by country of origin. These results shed some light on the lessons drawn from the microeconomic data discussed in the introduction. Even if terrorists are predominantly recruited among the relatively wealthy and educated social strata, as mentioned above, the secondary school enrollment rate and GDP per capita have a negative influence on the number of international terrorist events perpetrated by individuals from each country. This seemingly contradictory result is one of the predictions of the theoretical model presented above, and these empirical results thus provide some support for the latter.

The overall performance of these equations seems relatively weak, when looking at the pseudo- $R^{2} \mathrm{~s}$, but the likelihood ratio tests accept the overall significance of the equations. ${ }^{11}$ Moreover, we tried to choose between the two specifications presented using the $J$-test proposed by Davidson and MacKinnon (1982) for choosing between two non-nested models. The idea is that if one model is the correct one, then the fitted values from the other

\footnotetext{
${ }^{11}$ We ran some of these regressions using both Stata and E-Views, and found much higher pseudo- $R^{2}$ with the latter. We just present here the smaller of the two, for the sake of remaining on the safe side.
} 
model should not have any explanatory power when estimating the former. The first step is to estimate both models separately. The second step is to use the predicted dependent variable from model 2 as an auxiliary variable in model 1 (and vice versa). The third step consists of re-estimating model 1 and test whether or not the auxiliary variable makes a significant contribution to the explanation of the dependent variable. If this is true, the second model contains some relevant information not contained in the first model. In our analysis, we conclude that neither of the two models is preferred. We cannot choose between a model with ODA per capita or ODA as a percentage of GDP. Therefore, in the following section, we keep using these two models. Finally, we also performed a number of robustness checks. We use the gross tertiary school enrollment ratio instead of secondary education in table A.3. As mentioned above, the available evidence suggests that most of the terrorists have acquired some post-secondary education. Therefore, testing the impact of tertiary education is potentially an important check on the relevance of the model. The sample size is reduced to 164 countries. The results are qualitatively unchanged. We obtain roughly the same conclusion about the signs of the coefficients and their significance as with secondary education, although its significance level is lower. In particular, it is only significant at the $10 \%$ level when population size is dropped. Therefore, in our sample, the tertiary or the secondary education have roughly the same influence on terrorist activities.

The results of the foregoing section were estimated without correcting for endogeneity, but the next section shows that controling for that does not change significantly the diagnosis.

\section{Controling for Endogeneity}

We now test for endogeneity bias, using a version of the Hausman test. This procedure has two stages. First, a reduced-form equation is estimated for each endogenous variable, using exogenous variables as regressors. Then, the resulting residuals are computed and 
included in the initial model. If the residuals are jointly significant according to an $F$-test, then there is a significant endogeneity bias in the initial estimates. Moreover, adding these residuals to the equation allows to retrieve the unbiased coefficients, as shown by Blundell and Powell (2003) in a much more general setting.

\section{The Reduced Form ODA Equations}

In our setting, we first use the residuals from a Tobit regression explaining the amount of ODA per capita or that of ODA as a ratio to GDP for each country. Indeed, because our sample includes developed and developing countries, while only the latter receive any aid, this dependent variable is truncated at zero. In table 3, equation 5 is a reduced form equation aiming at explaining the level of ODA as a percentage of GDP with only exogenous variables and equation 6 the level of ODA per capita. We first use some economic variables, namely per capita GDP and population size which explain to some extent the need for aid. We include also a series of dummy variables, aimed mainly at controling for "militancy" and "educational capital”, the two exogenous parameters emphasized in the theoretical model. These dummy variables also control for several other country characteristics that might be relevant in the reduced-form ODA equation, like "civilization" and "historical ties" to colonial powers that are liable to affect the allocation of foreign aid across countries. The "China and India" variable helps us to control for any non-linear population size effect. ASEAN indicates members which joined that organization before 1990. This group represents potentially a “civilization” effect, as do "Latin America \& Carribeans”, "Sub Saharan Africa” and USSR. OECD and "Camp David" have already been used above for capturing certain "militancy" aspects. In addition, we add the under-5 infant mortality rate as an instrument for educational capital. This is a slow-moving indicator of human capital, which turns out to be significant in the reduced-form education equation.

Population and GDP per capita are significant with a negative sign in both equations 5 and 6, in agreement with conventional wisdom, while the infant mortality rate is significant 
with a positive sign in equation 5 only. ${ }^{12}$ The USSR variable is significant in equations 5 and 6 with a negative sign. So, during the period covered here, these countries seem to be discriminated against in terms of the amount of aid received, probably for cold-war related reasons. The Sub-Saharan Africa dummy is not significant in either equation, suggesting that these countries do not get more aid, as a ratio of GDP or per capita, than the rest of the world, after controling for per capita GDP, population size, and infant mortality. The "Camp David" countries, Egypt and Israel, and the West Bank \& Gaza Strip get more aid per capita than the others, given the controls included, but this is not significant when ODA is taken as a percentage of GDP.

\section{Table 3: Reduced-Form ODA}

Equation 5 : ODA \% of GDP

$\begin{array}{cccc} & \text { Coefficient } & \text { z-Statistic } & \text { p-value } \\ \text { Intercept } & 8.973 & 4.100 & 0.000 \\ \text { Population } & -7.20 \mathrm{E}-08 & -2.80 & 0.005 \\ \text { GDP p.c. } & -0.001 & -2.85 & 0.004\end{array}$

Under 5 Mortality

Rate (per 1000)

ASEAN

"Camp David"

China and India

Latin America

OECD

USSR

Sub-Saharan

West B. \& Gaza

Nb. Obs. $\mathrm{R}^{2}$

LR chi2(11)
0.054

$$
-1.430
$$

0.010

66.734

$-3.837$

$-16.321$

$-5.756$

$-0.836$

9.179

176

0.296

105.90
2.59

$-0.28$

0.001

2.33

$-1.61$

$-2.53$

$-1.81$

$-0.28$

0.87

(1)

Note: these equations have been estimated by a Tobit regression.

\footnotetext{
${ }^{12}$ The coefficient of GDP p.c. is very small, but highly significant. This coefficient is not unit-free, and its small size only reflects the fact that the aid to GDP ratio is a small number relative to GDP p.c.
}

Equation 6 : ODA p.c.

$\begin{array}{ccc}\text { Coefficient } & \text { z-Statistic } & \text { p-value } \\ 113.58 & 7.31 & 0.000 \\ -6.42 \mathrm{E}-07 & -3.60 & 0.000 \\ -0.005 & -3.06 & 0.002\end{array}$

-0.224
-27.672
96.866
610.298
-9.420
-141.845
-59.628
-10.968
150.853
176
0.240
92.13

$-1.56$

0.119

$-0.79 \quad 0.431$

0.999

1.85

0.064

3.08

0.002

0.108

$-0.57$

0.570

$-3.35$

0.001

$-2.70$

0.007

0.776

$-0.538$

0.591

2.07

0.038

0.000 


\section{Reduced-Form Equation Explaining the Secondary-School Enrollment Rate}

To explain the secondary school enrollment rate, we use an ordinary least squares regression. The dependent variable is the average ratio of secondary school enrollment over the period 1990-2004. We include the same explanatory variables as in the ODA equation: population, per capita GDP, under-5 infant mortality rate and dummy variables. The resulting model is globally significant.

\section{Table 4: Reduced-Form Secondary School Enrollment Ratio}

$\begin{array}{cccc}\text { Variable } & \text { Coefficient } & \begin{array}{c}\text { Equation } 7 \\ \text { t-Statistic }\end{array} & \text { p-value } \\ \text { Intercept } & 82.87 & 29.97 & 0.000 \\ \text { Population } & -1.95 \mathrm{E}-08 & -0.610 & 0.543 \\ \text { GDP p.c. } & 0.000 & 1.74 & 0.084 \\ \text { Infant Mortality } & -0.305 & -9.88 & 0.000 \\ \text { ASEAN } & -7.194 & -0.94 & 0.348 \\ \text { "Camp David" } & 11.81 & 1.03 & 0.305 \\ \text { China and India } & 15.318 & 0.42 & 0.673 \\ \text { Latin America } & -0.788 & -0.216 & 0.829 \\ \text { OECD } & 20.778 & 3.49 & 0.001 \\ \text { Sub-Saharan } & -5.904 & -1.31 & 0.191 \\ \text { USSR } & 20.101 & 4.16 & 0.000 \\ \text { West B. \& Gaza } & 9.307 & 0.58 & 0.562 \\ \text { Nb. Obs. } & 176 & & \\ \text { R } & 0.78 & & \\ \text { Prob (F-statistic) } & 0.000 & & \end{array}$

Note: Equation 7 is a least square regression estimated by maximum likelihood.

The population variable has no significant impact on the level of secondary school enrollment, while GDP per capita is significant at the $10 \%$ level only. The infant mortality rate has a highly significant negative impact, suggesting that health and education are moving in the same direction. Given population size, per capita GDP and infant mortality, OECD and USSR countries have a positive significant impact while the Sub-Saharan Africa dummy has a negative but insignificant coefficient. These signs do not come as a surprise, while the poor 
but insignificant African performance suggests that the substandard educational performance achieved in that continent is explained by the control variables included.

Final Test Controling for Endogeneity

Table 5: Controling for Endogeneity

\begin{tabular}{|c|c|c|c|c|c|c|}
\hline \multirow[b]{2}{*}{ Variables } & \multicolumn{3}{|c|}{ Equation 8} & \multicolumn{3}{|c|}{ Equation 9} \\
\hline & Coefficient & z-Statistics & p-value & Coefficient & z-Statistics & p-value \\
\hline Intercept & 8.91 & 3.84 & 0.000 & 5.993 & 5.29 & 0.000 \\
\hline GDP p.c. & $-7.98 \mathrm{E}-05$ & -2.11 & 0.035 & $-5.82 \mathrm{E}-05$ & -1.60 & 0.110 \\
\hline ODA (\% GDP) & -0.244 & -2.55 & 0.011 & - & - & - \\
\hline ODA p.c. & - & - & - & -0.027 & -3.07 & 0.002 \\
\hline \multicolumn{7}{|l|}{ Secondary Enrollment (\% } \\
\hline gross) & -0.080 & -3.61 & 0.000 & -0.042 & -3.50 & 0.001 \\
\hline West B. Gaza & 8.525 & 3.57 & 0.000 & 10.488 & 4.09 & 0.000 \\
\hline "Camp David" & 4.343 & 2.83 & 0.005 & 7.708 & 4.65 & 0.000 \\
\hline Sub-Saharan & -2.286 & -3.17 & 0.002 & -2.909 & -4.48 & 0.000 \\
\hline OECD & 3.016 & 3.17 & 0.002 & 1.207 & 1.24 & 0.213 \\
\hline Endog. Bias. Secondary & 0.074 & 3.05 & 0.002 & 0.052 & 3.11 & 0.002 \\
\hline Endog. Bias ODA (\% of GDP) & 0.138 & 1.31 & 0.190 & - & - & - \\
\hline Endog, Bias ODA p.c. & - & - & - & 0.009 & 0.92 & 0.358 \\
\hline Nb. Obs. & 176 & & & 176 & & \\
\hline Pseudo-R² & 0.080 & & & 0.088 & & \\
\hline LR-Stat chi2(9) & 62.70 & & 0.000 & 69.15 & & 0.000 \\
\hline Endogeneity $F$-test $(2,165)$ & 5.79 & & 0.004 & 5.27 & & 0.006 \\
\hline
\end{tabular}

Note: Equations 8 and 9 are negative binomial regressions estimated by maximum likelihood.

Table 5 presents the results of the test for endogeneity bias. We add the residuals from equations 5, 6 and 7 in tables 3 and 4, as appropriate, and their estimated coefficients provide estimates of the endogeneity bias for the corresponding variables. We find that the latter is significant for the secondary school enrollment rate and not for ODA, taken individually. However, the more relevant $F$-test for joint significance of the two added residuals confirms the presence of some endogeneity bias, in agreement with the theoretical framework presented above. Furthermore, for each of these variables, the sum of the estimated coefficient and the estimated bias adds up to almost the same number as the estimated coefficients for the same 
variables in equations 2 and 4, with the exception of the coefficient for Secondary Education in equation 9. This suggests that the addition of the residuals from the reduced-form equations are doing a pretty good job at controling for endogeneity. Then, the estimated coefficients of ODA, either as a percentage of GDP or per capita, and that of secondary education in equation 8 , are pretty close to the unbiased estimates. Hence, these results provide some support for the model presented above. The results of equation 9 are more ambiguous, as the estimated bias for secondary education suggests that the correction for endogeneity is less accurate. Nevertheless, the estimated (unbiased now) coefficient is still negative and significant, thus also providing some support for the model.

\section{Conclusion}

The empirical analysis performed in this paper provides some support for the views captured in the theoretical model presented above. This suggests that foreign aid is used (among other things) as a means to induce local governments to fight terrorism within their sphere of influence and thus to protect the political and economic interests of the donors. One of the key benefits of this approach against terrorism is that by reducing the flow of attacks at the source, it creates some positive externalities for the other potential targets. This is at variance with the seemingly more obvious self-protection approach, which creates negative externalities for the other potential targets, by diverting the flow of attacks onto them, as emphasized by Enders and Sandler (2006). Moreover, the model and the empirical results suggest that the donors can usefully earmark some of that aid for supporting the education sector. The theoretical model presented above helps us to understand why this result does not contradict the evidence found in various statistical data that terrorists are predominantly recuited among people from a relatively wealthy and educated background. What matters for the impact of foreign aid and education on the supply of terrorist attacks by country of origin is their effect on the government's behavior. The fact that there seems to be some correlation 
between the level of education of the individuals engaged in terrorism and their activism is irrelevant from the donor's point of view, as the local government will adjust its level of repression optimally as a function of the impact of education. Hence, beyond education per se, the model suggests that the donor can profitably earmark some funding for some activity that the recipient government values if its contribution is not perfectly fungible.

We thus found that aid can be pretty effective, and this stands in sharp contrast to the received wisdom from the so-called “aid-ineffectiveness” literature, which Easterly (2006) has recently surveyed. Our results thus help redress the confusion on which that literature is based, namely that aid is deemed "ineffective" because it is not achieving the objectives that it is not really trying to achieve. The proper methodology of economics is rather to infer from the data what objectives are being pursued, in the spirit of 'revealed preference' theory. Many foreign rulers of the past have used various means for protecting their interests abroad by inducing local regimes to act on their behalf. The most illuminating example is probably given by the Republic of Venice, which built a trading empire in the Mediterranean world in the late Middle Ages, between the thirteenth and the fifteenth centuries, while delegating to local rulers, and in particular the Byzantine Emperor, the task of protecting its traders by providing gifts and other incentives. The rich countries of the modern world have walked in their footsteps, on a much larger scale, coining the expression "foreign aid" as the name given to the underlying flow of gifts and presents. 


\section{Appendix}

\section{A.1: Joint Determination of the $a_{i} \mathrm{~s}$ and $H$}

Define the aggregate supply of terrorist attacks as:

$$
H^{S}=\sum_{i} h\left(\theta_{i}, \varepsilon_{i}, a_{i}\right)
$$

The $a_{i}$ s can then be derived implicitly, as (8) and (9) entail:

$$
\frac{\partial h\left(\theta_{i}, \varepsilon_{i}, a_{i}\right)}{\partial a_{i}}=\frac{-1}{\psi^{\prime}(H)},
$$

which can be solved to get $a_{i}=a\left(\theta_{i}, \varepsilon_{i}, H\right)$.

Then, equilibrium $H$ is found as the fixed point of the mapping:

$$
H^{S}=\sum_{i} h\left(\theta_{i}, \varepsilon_{i}, a\left(\theta_{i}, \varepsilon_{i}, H\right)\right) .
$$

If we assume that the second-order conditions hold everywhere, then this fixed-point exists and is unique, because the mapping (A.3) is monotonically decreasing in $H$ as $h\left(\theta_{i}, \varepsilon_{i}, a_{i}\right)$ is convex in $a_{i}$. 
A.2: Data

Table A.1: Number of Events per Source Country (1990:01-2004:03)

\begin{tabular}{|c|c|c|c|c|c|}
\hline Country & Number & Country & Number & Country & Number \\
\hline West Bank & 400 & Bahrain & 7 & Kuwait & 2 \\
\hline India & 227 & Ethiopia & 7 & Latvia & 2 \\
\hline Colombia & 97 & France & 7 & Liberia & 2 \\
\hline Israel & 58 & Rwanda & 7 & Macedonia & 2 \\
\hline Iraq & 49 & Venezuela & 7 & Malaysia & 2 \\
\hline Yemen & 49 & Cambodia & 6 & Netherland & 2 \\
\hline Algeria & 47 & Ireland & 6 & Panama & 2 \\
\hline Pakistan & 45 & Italy & 6 & Switzerland & 2 \\
\hline Angola & 41 & Jordan & 6 & Armenia & 1 \\
\hline Russian F. & 33 & Bangladesh & 5 & Croatia & 1 \\
\hline Spain & 31 & Ecuador & 5 & Czech Rep. & 1 \\
\hline Turkey & 28 & Iran & 5 & Emirates & 1 \\
\hline Nigeria & 26 & Japan & 5 & Eritrea & 1 \\
\hline Sri Lanka & 25 & Lebanon & 4 & Guinea & 1 \\
\hline Peru & 22 & Sudan & 4 & Honduras & 1 \\
\hline Sierra Leone & 21 & U.S. & 4 & Libya & 1 \\
\hline Egypt & 19 & Austria & 3 & Morocco & 1 \\
\hline Philippines & 19 & Nepal & 3 & Nicaragua & 1 \\
\hline Greece & 11 & Argentina & 2 & Norway & 1 \\
\hline Indonesia & 11 & Azerbaijan & 2 & Poland & 1 \\
\hline Tadjikistan & 11 & Bolivia & 2 & Senegal & 1 \\
\hline Burundi & 10 & Chad & 2 & Sweden & 1 \\
\hline Uganda & 10 & Chile & 2 & Tanzania & 1 \\
\hline Georgia & 9 & China & 2 & Thailand & 1 \\
\hline Saudi Arabia & 9 & El Salvador & 2 & Tunisia & 1 \\
\hline U.K. & 9 & Germany & 2 & Zambia & 1 \\
\hline South Africa & 8 & Kenya & 2 & & \\
\hline
\end{tabular}

Source: ICT (http://www.ict.org.il) 
Table A.2: Summary Statistics

\begin{tabular}{|l|c|c|c|c|c|}
\hline & $\mathbf{N}$ & Minimum & Maximum & Mean & $\begin{array}{c}\text { Standard } \\
\text { Deviation }\end{array}$ \\
\hline Number of events & 176 & 0 & 400 & 8.38 & 36.25 \\
\hline Population & 176 & 19850 & 1224587494.40 & 32253573.83 & 120880525.64 \\
\hline GDP per capita & 176 & 96.86 & 38952.22 & 5495.69 & 8350.54 \\
\hline ODA per capita & 176 & 0 & 490.45 & 52.96 & 77.40 \\
\hline $\begin{array}{l}\text { ODA (\% of GDP) School } \\
\text { Secondary }\end{array}$ & 176 & 5.50 & 151.33 & 67.07 & 32.90 \\
\hline $\begin{array}{l}\text { Enrollment (\% gross) } \\
\text { Rate (per 1000) Mortality }\end{array}$ & 176 & 4.525 & 290.95 & 67.713 & 67.027 \\
\hline
\end{tabular}

Source: Computed from Table A.1 and World Development Indicators on Line.

\section{A.3: Additional Estimates}

Table A.3: Number of Terrorist Events Originating From Each Country (Without the Dummy Variables)

\begin{tabular}{ccccccc} 
& \multicolumn{3}{c}{ Equation A.1 } & \multicolumn{3}{c}{ Equation A.2 } \\
Variables & Coefficient & $\mathbf{z}$-Statistics & p-Value & Coefficient & z-Statistics & p-Value \\
Intercept & 1.840 & 3.36 & 0.001 & 1.794 & 3.28 & 0.001 \\
GDP p.c. & $-8.31 \mathrm{E}-05$ & -2.81 & 0.005 & $-6.04 \mathrm{E}-05$ & -1.98 & 0.048 \\
& & & & & & - \\
ODA (\% GDP) & -.026 & -1.08 & 0.280 & - & - & 0.267 \\
& & - & - & .003 & 1.11 & \\
ODA p.c. & - & - & & & & 0.540 \\
condary Enrollment & & & 0.147 & .006 & 0.61 & \\
(\% gross) & .012 & 1.45 & & 176 & & \\
Nb. Obs. & 176 & & & 0.008 & & 0.0995 \\
Pseudo-R & 0.007 & & 0.109 & 6.26 &
\end{tabular}

Note: equations A.1 and A.2 are negative binomial regressions estimated by maximum likelihood. 


\section{Table A.4: Number of Terrorist Events Originating From Each Country (With Tertiary Education Variable)}

\begin{tabular}{ccccccc} 
& \multicolumn{3}{c}{ Equation A.3 } & \multicolumn{3}{c}{ Equation A.4 } \\
Variables & Coefficient & $\mathbf{z}$-Statistics & $\mathbf{p}$-Value & Coefficient & z-Statistics & p-Value \\
Intercept & 3.025 & 7.63 & 0.000 & 3.197 & 7.65 & 0.000 \\
GDP p.c. & -0.001 & -2.89 & 0.004 & $-8.4 \mathrm{E}-05$ & -2.23 & 0.026 \\
ODA (\% GDP) & -.091 & -2.91 & 0.004 & - & - & - \\
ODA p.c. & - & - & - & -.019 & -4.68 & 0.000 \\
Tertiary Enrollment & & & & & & \\
(\% Gross) & -.028 & -2.15 & 0.031 & -.024 & -1.72 & 0.085 \\
West B. Gaza & 5.652 & 2.56 & 0.010 & 8.376 & 3.76 & 0.000 \\
"CampDavid" & 3.829 & 2.34 & 0.020 & 6.870 & 4.06 & 0.000 \\
Sub-Saharan & -.336 & -0.50 & 0.614 & -1.224 & -2.52 & 0.012 \\
OECD & 2.409 & 2.28 & 0.023 & 1.239 & 1.29 & 0.196 \\
Nb. Obs. & 164 & & & 164 & & \\
Pseudo-R ${ }^{2}$ & 0.055 & & & 0.067 & & \\
LR-Stat & 42.04 & & 0.000 & 51.44 & &
\end{tabular}

Note: Equation A.3 and A.4 are negative binomial regressions estimated by maximum likelihood

Acknowlegments: A helpful econometric discussion with Pierre Dubois is gratefully acknowledged, as well as useful comments by Ruxanda Berlinschi, without implicating their responsibility in any way. This paper is part of the "Polarization and Conflict” project funded by the EU and has been presented at the Gaillac workshop on June 7, 2007. Comments by Matteo Cervelatti, Joan Esteban, Ragnhild Nordås, Gudrun Østby, David Schmeidler and Gerald Schneider, as well as comments by two anonymous referees and the editor in chief, William F. Shugart II, are gratefully acknowledged, without implicating. 


\section{References}

Abadie, A. (2006). Poverty, Political Freedom, and the Roots of Terrorism. American Economic Review (AEA Papers \& Proceedings), 96(2), 50-56.

Adam, C. S., \& O’Connell, S. (1999). Aid, Taxation and Development in Sub-Saharan Africa. Economics and Politics, 11(3), 225-253.

Alesina, A., \& Dollar, D. (2000). Who Gives Aid to Whom and Why? Journal of Economic Growth, 5, 33-63.

Azam, J.-P. (2005). Suicide-Bombing as Inter-Generational Investment. Public Choice, 122(1-2), 177-198.

Azam, J.-P., \& Delacroix, A. (2006). Aid and the Delegated Fight Against Terrorism. Review of Development Economics, 10(2), 330-344.

Azam, J.-P., \& Laffont, J.-J. (2003). Contracting for Aid. Journal of Development Economics, 70(1), 25-58.

Azam, J.-P., \& Saadi-Sedik, T. (2004). Aid v. Sanctions for Taming Oppressors: Theory and Case Study of the Iraqi Kurds. Defence and Peace Economics, 15(4), 343-364.

Basouchoudhary, A., \& Shughart, W. F. (2007). On Ethnic Conflict and the Origins of Terrorism. Unpublished, University: University of Mississippi.

Berman, E., \& Laitin, D.D. (2005). Hard Targets: Theory and Evidence on Suicide Attacks. NBER WP 11740.

Berthélemy, J.-C. (2006). Bilateral Donor’s Interest vs. Recipients’ Development Motives in Aid Allocation: Do All Donors Behave the Same? Review of Development Economics, 10(2), 179-194.

Berthélemy, J.-C., \& Tichit, A. (2004). Bilateral Donors' Aid Decisions-A ThreeDimensional Panel Analysis. International Review of Economics and Finance, 13, 253274. 
Blomberg, S. B., Hess, G.D. \& Weerapan, A. (2004). Economic Conditions and Terrorism. European Journal of Political Economy, 20(2), 463-478.

Bloom, M. (2005). Dying to Kill. The Allure of Suicide Terrorism. New York: Columbia University Press.

Blundell, R., \& Powell, J.L. (2003). Endogeneity in Non Parametric and Semi Parametric Regression Models. In M. Dewatripont, L. Hansen \& S.J. Turnovsky (Eds.), Advances in Economics and Econometrics: Theory and Applications, vol. II, (pp.312-357). Cambridge: Cambridge University Press.

Bueno de Mesquita, E. (2005). The Quality of Terror. American Journal of Political Science, 49(3), 515-530.

Burnside, C. \& Dollar, D. (2000). Aid, Policies, and Growth. American Economic Review, 90, 847-868.

Cameron, A. C., \& Trivedi, P.K. (1986). Econometric Models Based on Count Data: Comparisons and Applications of some Estimators Tests. Journal of Applied Econometrics, 1(1), 29-53.

Chauvet, L. (2002). “Socio-Political Instability and the Allocation of International Aid by Donors. European Journal of Political Economy, 19, 33-59.

Collier, P. (2007). The Bottom Billion. Why the Poorest Countries Are Failing and What Can Be Done About It. Oxford: Oxford University Press.

Crain, N.V., \& Crain, M.M. (2006). Terrorized Economies. Public Choice, 128, 317-349.

Davidson, R., \& MacKinnon, J.G. (1982). Some Non-Nested Hypothesis Tests and the Relations among Them. Review of Economic Studies, 49, 551-565.

Drakos, K., \& Gofas, A. (2006). "In Search of the Average Transnational Terrorist Attack Venue. Defence and Peace Economics, 17(2), 73-93.

Easterly, W. (2006). The White Man's Burden. Why the West's Effort to Aid the Rest Have Done so Much Ill and so Little Good. New York: Penguin Press. 
Enders, W. \& Sandler, T. (2006). The Political Economy of Terrorism. Cambridge: Cambridge University Press.

Ferrero, M. (2006). Martyrdom Contracts. Journal of Conflict Resolution, 50(6), 855-877.

Fleck, R.K., \& Kilby, C. (2006a). How Do Political Changes Influence US Bilateral Aid Allocation? Evidence from Panel Data. Review of Development Economics, 10(2), 210223.

Fleck, R.K., \& Kilby, C. (2006b). World Bank Independence: A Model and Statistical Analysis of U.S. Influence. Review of Development Economics, 10(2), 224-240.

Frey, B.S. (2004). Dealing with Terrorism: Stick or Carrot? Cheltenham: Edward Elgar.

Frey, B.S., Luechinger, S., \& Stutzer, A. (2007). Calculating Tragedy: Assessing the Cost of Terrorism. Journal of Economic Surveys, 21(1), 1-24.

Hassan, N. (2001). An Arsenal of Believers. The New Yorker, November 19.

Krueger, A.B. (2003). Poverty Doesn’t Create Terrorism. New York Times, May 29.

Krueger, A.B., \& Laitin, D.D. (2003). Kto Kogo? A Cross-Country Study of the Origins and Targets of Terrorism. Unpublished, Princeton University.

Krueger, A.B., \& Maleckova, J. (2003). Education, Poverty and Terrorism: Is There a Causal Connection? Journal of Economic Perspectives, 17(4), 119-144.

Kurrild-Klitgaard, P., Justesen, M.K., \& Klemmensen, R. (2006). The Political Economy of Freedom, Democracy and Transnational Terrorism. Public Choice, 128, 289-315.

Li, Q. (2005). Does Democracy Promote or Reduce Transnational Terrorist Incidents? Journal of Conflict Resolution, 49(2), 278-297.

McCullagh, P., \& Nelder, J.A. (1989). Generalized Linear Models. London: Chapman and Hall.

Paz, R. (2000). Higher Education and the Development of Palestinian Islamic Groups. Middle East Review of International Affairs, 4, 81-94. 
Reuter, C. (2004). My Life is a Weapon. A Modern History of Suicide Bombing. Princeton: Princeton University Press.

Sageman, M. (2004). Understanding Terror Networks. Philadelphia: University of Pennsylvania Press.

Siqueira, K., \& Sandler, T. (2006). Terrorists versus the Government: Strategic Interaction, Support, and Sponsorship. Journal of Conflict Resolution, 50(6), 878-898.

Stern, J. (2003). Terror in the Name of God. Why Religious Militants Kill. New York: HarperCollins.

Svensson, J. (1999). Aid, Growth and Democracy. Economics and Politics, 11(3), 275-297.

Svensson, J. (2000). When is Foreign Aid Policy Credible? Aid Dependence and Conditionality. Journal of Development Economics, 61(1), 61-84.

Svensson, J. (2003). Why Conditional Aid Does not Work and What Can Be Done about it? Journal of Development Economics, 70(2), 381-402.

Testas, A. (2004). Determinants of Terrorism in the Muslim World: An Empirical CrossSectional Analysis. Terrorism and Political Violence, 16(2), 253-273.

Wintrobe, R. (2006). Extremism, Suicide Terror, and Authoritarianism. Public Choice, 128, 168-195.

World Bank (1998). Assessing Aid: What Works, What Doesn't, and Why. A World Bank Policy Research Report, Washington, D.C.: World Bank. 